\title{
Prognostic value of systemic immune-inflammation index in patients with urologic cancers: a meta-analysis
}

\author{
Yilong Huang ${ }^{1,2}$, Yunfeng $\mathrm{GaO}^{3}$, Yushen $\mathrm{Wu}^{4^{*}}$ and Huapeng $\mathrm{Lin}^{5^{*}}$ (1)
}

\begin{abstract}
Background: Several studies have reported that the systemic immune-inflammation index (SII) is associated with the prognosis of patients with urologic cancers (UCs). The aim of this study was to systematically evaluate the prognostic value of SII in UC patients.

Methods: We searched public databases for relevant published studies on the prognostic value of SII in UC patients. Hazard ratios (HRs) and 95\% confidence intervals (Cls) were extracted and pooled to assess the relationships between SIl and overall survival (OS), progression-free survival (PFS), cancer-specific survival (CSS), overall response rate (ORR) and disease control rate (DCR).

Results: A total of 14 studies with 3074 patients were included. From the pooled results, we found that high SII was associated with worse overall survival (OS) in patients with UC (HR 2.58, 95\% Cl 1.59-4.21). Patients with high SIl values also had poorer PFS (HR 1.92, 95\% Cl 1.29-2.88) and CSS (HR 2.58, 95\% Cl 1.36-4.91) as well as lower ORRs (HR 0.40, $95 \% \mathrm{Cl} 0.22-0.71$ ) than patients with low SII values. In addition, the subgroup analysis of OS and PFS showed that the prognosis of patients with high SII was worse than that of patients with low SII.
\end{abstract}

Conclusions: SII might be a promising noninvasive predictor in patients with UC. However, more samples and multicenter studies are needed to confirm the effectiveness of SII in predicting the prognosis of patients with UC.

Keywords: Urologic cancer, Meta-analysis, Prognosis, Systemic immune-inflammation index (SII)

\section{Background}

Urologic cancer is a group of cancers that occur in the urinary system. The incidence of urologic cancer is still high. Kidney cancer is the seventh most common malignancy in men and the ninth most common malignancy in women globally [1]. Bladder cancer is the fourth and eleventh most common cancer among men and women

\footnotetext{
*Correspondence: arenasall@163.com; linhuapeng11@163.com

${ }^{4}$ Chongqing Key Laboratory of Molecular Oncology and Epigenetics, The First Affiliated Hospital of Chongqing Medical University, 1 Youyi Road, Yuzhong District, Chongqing 400042, People's Republic of China

${ }^{5}$ Department of Intensive Care Unit, Affliated Hangzhou First People's

Hospital, Zhejiang University School of Medicine, 261 Huansha Road, Hangzhou 310006, Zhejiang, People's Republic of China

Full list of author information is available at the end of the article
}

worldwide [2]. Prostate cancer is the most common type of cancer in men and the second leading cause of cancerrelated death in men [2]. Despite advances in the early diagnosis and treatment of urologic cancers, the prognosis remains poor due to local recurrence or distal metastasis $[3,4]$. Therefore, noninvasive detection tools such as serum biomarkers are increasingly valued for their simplicity and predictive value.

Inflammation is an important predictor of tumor invasion, progression and metastasis [5]. Therefore, a series of biological indicators based on inflammation and/or nutritional status, such as the neutrophil-to-lymphocyte ratio (NLR) and platelet-to-lymphocyte ratio (PLR), have been reported as efficient tumor biomarkers [6-8]. The systemic immune-inflammation index (SII), as a relatively

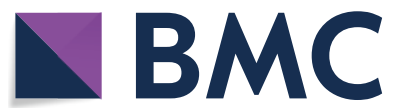

(c) The Author(s) 2020. This article is licensed under a Creative Commons Attribution 4.0 International License, which permits use, sharing, adaptation, distribution and reproduction in any medium or format, as long as you give appropriate credit to the original author(s) and the source, provide a link to the Creative Commons licence, and indicate if changes were made. The images or other third party material in this article are included in the article's Creative Commons licence, unless indicated otherwise in a credit line to the material. If material is not included in the article's Creative Commons licence and your intended use is not permitted by statutory regulation or exceeds the permitted use, you will need to obtain permission directly from the copyright holder. To view a copy of this licence, visit http://creativeco mmons.org/licenses/by/4.0/. The Creative Commons Public Domain Dedication waiver (http://creativecommons.org/publicdomain/ zero/1.0/) applies to the data made available in this article, unless otherwise stated in a credit line to the data. 
new inflammatory index based on peripheral lymphocyte, neutrophil, and platelet counts, was evaluated to have high diagnostic value for the prognosis of cancer $[9,10]$. Poor outcomes have been recently reported in patients with high SII values based on studies of other cancers, such as respiratory system cancers and digestive system cancers $[7,8,11]$. There is still a debate for the use of SII in urologic cancers, although an increasing number of studies has been performed on this topic, and the sample size in the existing research is not that large [12, 13]. Therefore, we conducted a meta-analysis to investigate the prognostic role of SII in patients with urologic cancers.

\section{Methods}

\section{Search strategy}

To identify relevant available articles irrespective of language, the electronic databases of EMBASE, PubMed and the Cochrane Library were rigorously searched from inception to April 2020. The search terms included 'urinary cancer', 'bladder cancer', 'kidney cancer', 'prostate cancer' and 'systemic immune-inflammation index' or 'SII. Both MeSH terms and entry terms were utilized in the literature search. In addition, we screened all the references of the relevant studies and reviews to attain additional eligible studies.

\section{Inclusion and exclusion criteria}

The studies included in the meta-analysis met the following inclusion criteria: (1) adult patients who were diagnosed with urinary cancer; (2) SII, which was defined as the multiplication of the neutrophil and platelet counts divided by the lymphocyte count, was available or could be calculated, and SII was presented as a binary variable with a selected cut-off value; (3) the primary outcome was overall survival (OS), and the relationship between OS and SII was analyzed; (4) the hazard ratios (HRs) with the 95\% confidence intervals (95\% CIs) were available or could be calculated; and (5) the study quality was assessed in accordance with the Newcastle-Ottawa quality assessment scale, and the included studies had a score of no less than 6.14 The exclusion criteria were as follows: (1) studies on the children or pregnant women; (2) experimental studies on the cell lines or animals; (3) the use of anti-inflammatory or immune-suppressive drugs in the studies; and (4) publication types including case reports, editorials, meta-analyses and reviews. When duplicated studies from the same population were included, the latest and most complete study was included.

\section{Data extraction}

The following information was extracted from the selected studies: first author, publication year with the country or region of the study, study type, kind of cancer, number of samples, age of patients, follow-up time, cutoff value of SII and how the cut-off was selected, treatment that the patients received, stage of the cancer and data on the primary and secondary outcomes. Analysis results from univariate and multivariate analyses were extracted. Effect values in multivariate analysis were preferred, and subgroup analysis according to the different analysis methods was performed. If the HRs with the $95 \%$ CI were not available, they were calculated from survival curves using Engauge Digitizer. Two researchers extracted the information independently, and any disagreements were resolved by a third individual.

\section{Statistical analysis}

The meta-analysis was performed using RevMan software (version 5.3; The Nordic Cochrane Center, Cochrane Collaboration, Copenhagen, Denmark). The HRs and 95\% CIs from the survival analyses of the included studies were pooled to assess the prognostic role of SII in urinary cancer patients, and the odds ratios (ORs) with the corresponding CIs were pooled in the analysis of binary variables. The heterogeneity of the results across studies was qualitatively tested using Cochran's Q-test and quantified using I2 statistics. I2 statistics of $25 \%, 50 \%$ and $75 \%$ represent the low, moderate and high levels of heterogeneity, respectively. A fixed-effects model was used when there was low heterogeneity; otherwise, a random-effects model was used. Publication bias was evaluated by funnel plots. Sensitivity analysis was performed by omitting individual studies one by one to assess the reliability of the results. A P value less than 0.05 was considered statistically significant.

\section{Results}

\section{Search results and study characteristics}

The search yielded 184 studies, of which 76 studies were from the PubMed database and 108 studies were from the EMBASE database. No available studies were obtained from the Cochrane Library database. A total of 14 studies (11 full-text studies and 3 conference abstracts) were finally included in the present metaanalysis $[9,12,13,14-24]$. Figure 1 shows the study selection process. There were 7 studies on patients with renal cancer, 5 of which were studies on advanced carcinoma, 1 on resectable carcinoma and the last one had unclear tumor stages. Among the studies on advanced renal cancer, the primary treatments were immunotherapy, targeted therapy and extensive surgeries. Three studies were on prostate cancer, and all of the included patients from these studies were diagnosed with metastasis. Abiraterone, docetaxel and their combination 


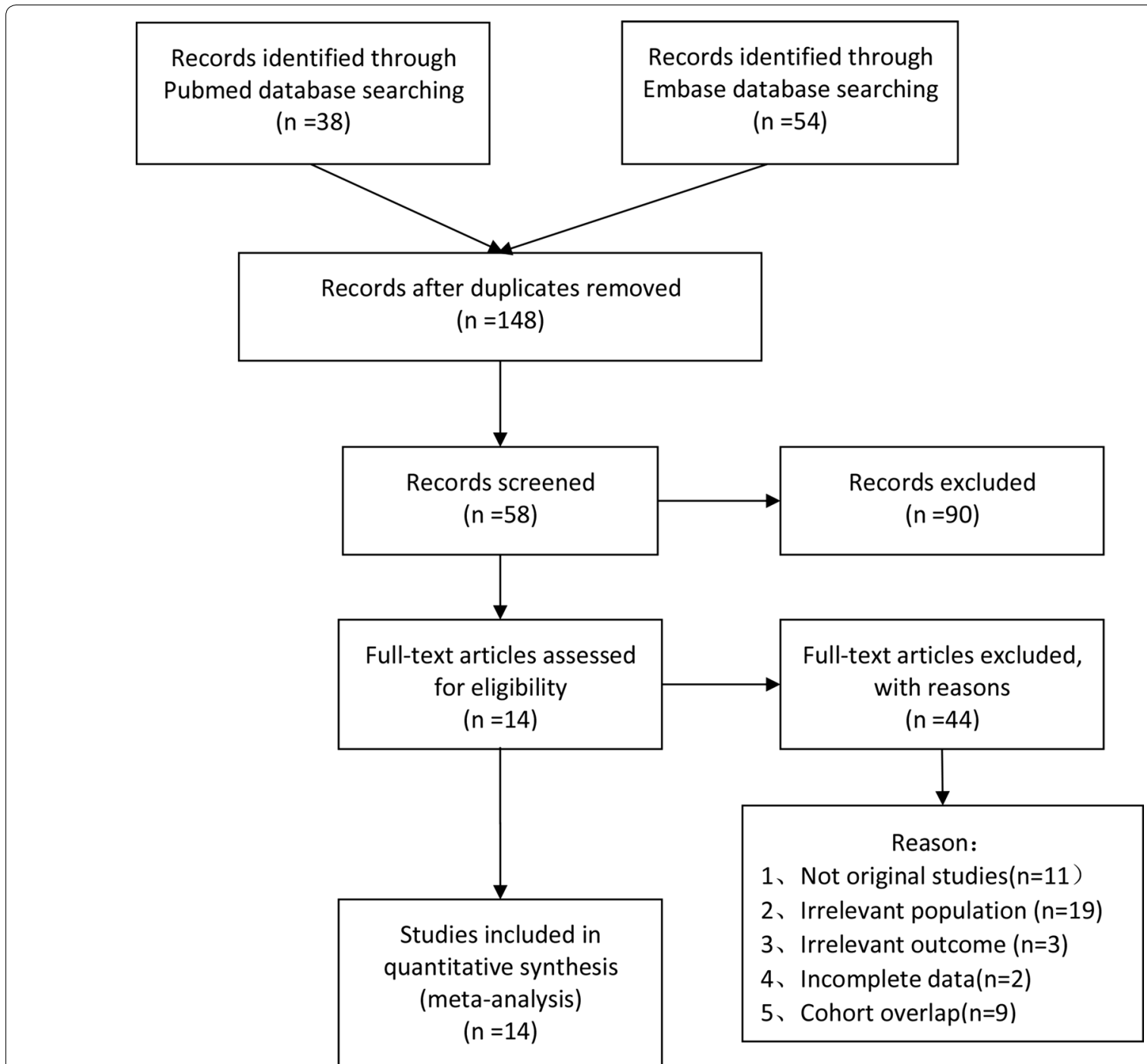

Fig. 1 Flow chart for the study selection

were selected as the first-line treatment in the three prostate cancer studies. Two studies evaluated the prognostic value of SII in patients with muscle-invasive bladder cancer after radical cystectomy. Two studies were conducted on patients with tumors from different organs. Several studies evaluated the prognostic role of other serum inflammation biomarkers. NLR (7 studies) and PLR (6 studies) were the most frequently studied biomarkers in previous studies. Three studies reported the association of the monocyte-to-lymphocyte ratio (MLR)/lymphocyte-to-monocyte ratio (LMR) and prognosis, and the prognostic role of the C-reactive protein-to-albumin ratio (CAR) was assessed in two studies. The details of the characteristics of the included studies are presented in Table 1.

\section{Impact of SII on OS}

The prognostic value of SII was evaluated in all 14 included studies. As shown in Fig. 2a, patients with high SII had a significantly better overall survival than patients with low SII (HR 2.58, 95\% CI 1.59-4.21, $\mathrm{p}=0.0001$ ). High heterogeneity was observed; therefore, a randomeffects model was used in the analysis. There was no significant publication bias, as shown in the funnel plot (Fig. 2b). Then, we performed the subgroup analysis (Table 2). The subgroup analysis according to the cancer type, study type, cut-off value of SII and analysis method 
Table 1 Characteristics of included studies

\begin{tabular}{|c|c|c|c|c|c|c|c|c|}
\hline \multirow{2}{*}{$\begin{array}{l}\text { Study/year } \\
\text { Ugo De Giorgi (2019) }\end{array}$} & \multirow{2}{*}{$\begin{array}{l}\text { Cancer type } \\
\text { mRCC }\end{array}$} & \multirow{2}{*}{$\begin{array}{l}\text { Country/region } \\
\text { Italy }\end{array}$} & Study type & Included period & No of samples & Age & \multicolumn{2}{|c|}{ Primary outcome } \\
\hline & & & $P$ & $2015-2016$ & 313 & 65 & \multicolumn{2}{|c|}{ OS/PFS } \\
\hline Cristian Lolli (2016) & $\mathrm{mRCC}$ & Italy & $\mathrm{R}$ & NA & 335 & 63 & \multicolumn{2}{|c|}{ OS/PFS } \\
\hline Wentao Zhang (2019) & $\mathrm{BC}$ & China & $\mathrm{R}$ & 2015-2019 & 209 & 66.7 & \multicolumn{2}{|c|}{ OS } \\
\hline Rebuzzi S.E. (2020) & $\mathrm{mRCC}$ & Italy & $\mathrm{R}$ & 2016-2019 & 189 & 69 & \multicolumn{2}{|l|}{ OS } \\
\hline Pawel Chrom (2018) & $\mathrm{mRCC}$ & Poland & $\mathrm{R}$ & 2008-2016 & 502 & NA & OS & \\
\hline Cristian Lolli (2016) & $\mathrm{mCRPC}$ & Italy & $\mathrm{R}$ & $2011-2015$ & 230 & 74 & OS & \\
\hline $\begin{array}{l}\text { Sacit Nuri Gorgel } \\
\qquad(2019)\end{array}$ & $\mathrm{MIBC}$ & Turkey & $\mathrm{R}$ & $2006-2018$ & 191 & 62.1 & $\mathrm{OS} / \mathrm{C}$ & SS \\
\hline Ghanghoria A (2020) & $\mathrm{RCC}$ & India & $\mathrm{R}$ & NA & 33 & NA & OS & \\
\hline Hau-Chern Jan (2018) & UTUC & Taiwan & $\mathrm{R}$ & $2007-2017$ & 424 & 70 & $\mathrm{OS} / \mathrm{F}$ & $\mathrm{FS} / \mathrm{CSS}$ \\
\hline Ya-nan Man (2019) & $\mathrm{mCRPC}$ & China & $\mathrm{R}$ & $2010-2018$ & 179 & 70 & OS & \\
\hline Emin Ozbek (2019) & $\mathrm{RCC}$ & Turkey & $\mathrm{R}$ & NA & 176 & 62 & $\mathrm{OS} /[$ & SSS \\
\hline Liancheng Fan (2017) & mCRPC & China & $\mathrm{R}$ & $2013-2017$ & 104 & 72 & $\mathrm{OS} / \mathrm{F}$ & \\
\hline Palacka P (2017) & $\mathrm{mUC}$ & Slovakia & $\mathrm{R}$ & 2000-2015 & 185 & NA & $\mathrm{OS} / \mathrm{F}$ & \\
\hline $\begin{array}{l}\text { Sasanka Kumar Barua } \\
\text { (2019) }\end{array}$ & $\mathrm{mRCC}$ & India & $\mathrm{R}$ & $2012-2017$ & 31 & 60 & $\mathrm{OS} / \mathrm{F}$ & \\
\hline Follow-up (months) & Cut-off & Cut-off selection & Treatment Methods & Stage/T stage & MVA & NOS & core & $\begin{array}{l}\text { Conference } \\
\text { summary }\end{array}$ \\
\hline 24 & 1375 & X-tile & Mix & T4 & Y & 7 & & $N$ \\
\hline 49 & 730 & X-tile & No surgery & $\mathrm{T} 4$ & $\mathrm{~N}$ & 7 & & $\mathrm{~N}$ \\
\hline $1-48$ & 507 & X-tile & Mix & Tis-T4 & Y & 6 & & $\mathrm{~N}$ \\
\hline NA & 1375 & NA & No surgery & $\mathrm{T} 4$ & $\mathrm{~N}$ & NA & & Y \\
\hline 52.5 & 730 & X-tile & Mix & $\mathrm{T} 4$ & Y & 8 & & $\mathrm{~N}$ \\
\hline $1-30$ & 535 & X-tile & No surgery & $\mathrm{T} 4$ & Y & 7 & & $\mathrm{~N}$ \\
\hline 37 & 843 & $\mathrm{ROC}$ & Surgery & T2-T4 & Y & 8 & & $\mathrm{~N}$ \\
\hline $6.8-38.6$ & 8.67 & NA & Surgery & NA & $N$ & NA & & Y \\
\hline $1-120$ & 580 & $\mathrm{ROC}$ & Surgery & Ta-T4 & Y & 8 & & $\mathrm{~N}$ \\
\hline 24 & 535 & NA & No surgery & $\mathrm{T} 4$ & Y & 7 & & $\mathrm{~N}$ \\
\hline NA & $830 / 850$ & $\mathrm{ROC}$ & Surgery & T1-T4 & $\mathrm{N}$ & 7 & & $\mathrm{~N}$ \\
\hline $1-50$ & 200 & $\mathrm{ROC}$ & No surgery & $\mathrm{T} 4$ & Y & 7 & & $\mathrm{~N}$ \\
\hline 10 & NA & NA & No surgery & T4 & Y & NA & & Y \\
\hline NA & 883 & $\mathrm{ROC}$ & Surgery & T4 & Y & 6 & & $\mathrm{~N}$ \\
\hline
\end{tabular}

mRCC: metastatic renal cell cancer; BC: bladder cancer; mCRPC: metastatic castration-resistant prostate cancer; MIBC: muscle invasive bladder cancer; RCC: renal cell cancer; UTUC: Upper-Tract Urothelial Carcinoma; mUC: metastatic urothelial carcinoma; P: prospective; R:retrospctive; OS: overall survival; PFS: progression-free survival; CSS: cancer-specific survival; DSS: disease-specific survival; MVA: multivariate analysis; NOS: Newcastle-Ottawa quality assessment scale; Y:yes; N: non

showed that the poorer prognosis was persistent in patients with high SII than in patients with low SII. All the above analysis results were evaluated to be reliable after the sensitivity analysis.

\section{Impact of SII on progression-free survival (PFS)}

We performed the analysis with PFS as the secondary outcome. As shown in Table 3, patients with high SII had a worse prognosis than patients with low SII (HR 1.92, 95\% CI 1.29-2.88, $\mathrm{p}=0.001$ ). Subsequently, subgroup analysis was performed according to the cancer type, treatment type, study type and analysis method (Table 4). A significant difference between patients with high and low SII in terms of PFS was observed in almost all the subgroup analyses, except for the analysis in prospective studies or in patients who underwent surgery.

\section{Impact of SII on cancer-specific survival (CSS), overall response rate (ORR) and disease control rate (DCR)}

As shown in Table 3, patients with low SII had a significantly better cancer-specific survival than patients with high SII (HR 2.58, 95\% CI 1.36-4.91, p=0.004). Low SII was evaluated to be associated with a higher ORR (OR $0.40,95 \%$ CI $0.22-0.71, p=0.002$ ). However, the difference in terms of DCR was not significant between 


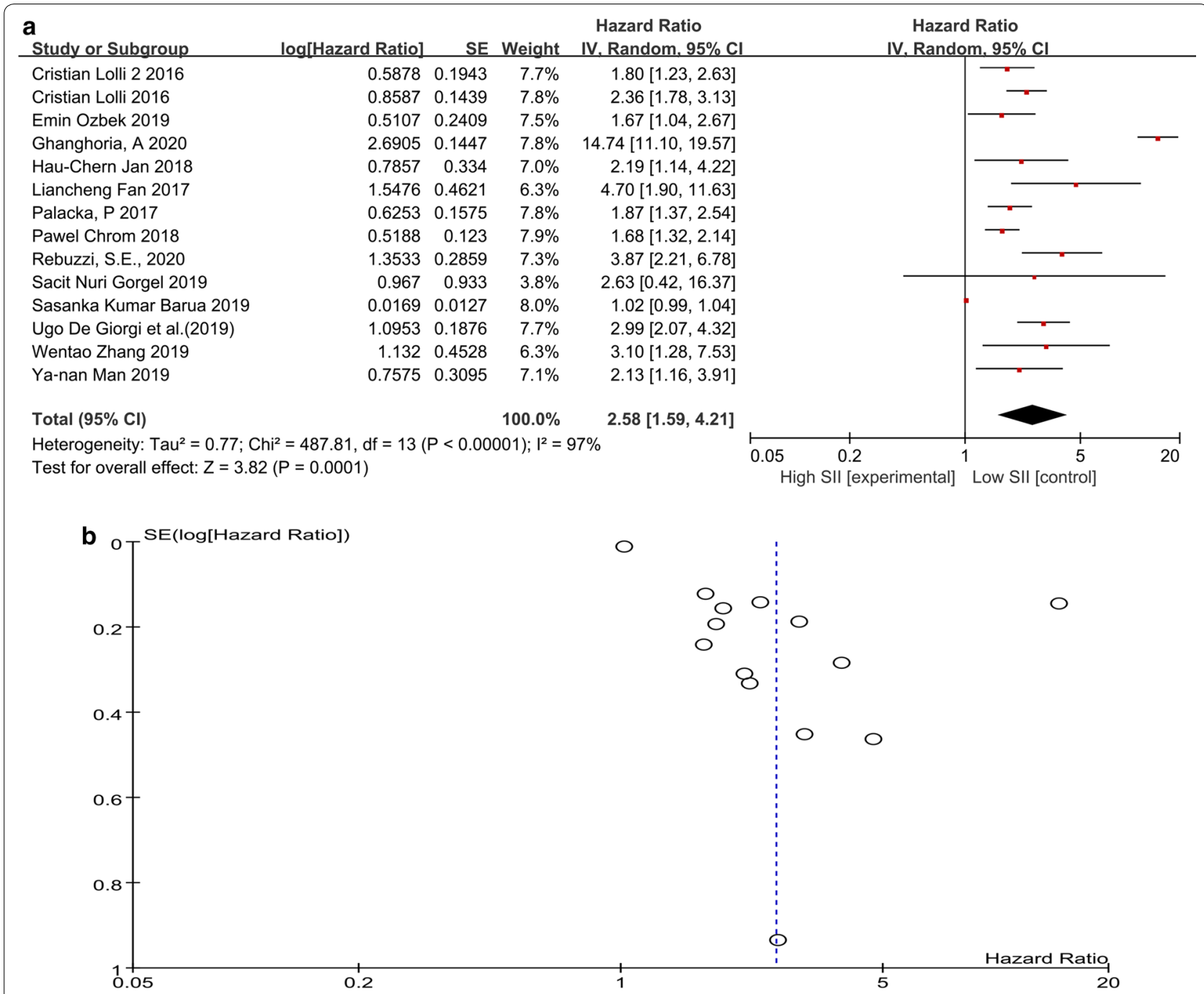

Fig. 2 a Forest plot and $\mathbf{b}$ funnel plot of the overall survival in patients of high and low SII

patients with high and low SII (OR 0.93, 95\% CI 0.11$8.05, \mathrm{p}=0.950)$.

\section{Discussion}

To our knowledge, this is the first meta-analysis that analyzed the prognostic value of SII in urologic cancers. A total of 14 published articles or conferences with 3074 cases were included in this study. From the pooled results, we found that UC patients with a high SII value had a worse prognosis for OS (HR 2.58, 95\% CI 1.594.21). Moreover, we performed subgroup analysis to assess the prognostic significance of SII. The subgroup analysis results showed that high SII was a prognostic marker for worse OS in PC (prostate cancer) and UC (urothelial carcinoma). Similarly, high SII was also negatively correlated with PFS, CSS, and ORR. Considering the above results, SII could serve as a prognostic factor for urinary cancers.

Currently, an increasing number of biological markers have been applied in clinical work due to their inexpensiveness and ready availability. The lymphocyte count, plasma fibrinogen, NLR, PLR and LMR have been proven to be valuable for the prognosis of cancer patients. However, when only one or two parameters were involved, these predictors became unstable and tended to be susceptible to the influence of other confounding factors [25]. SII, defined as P (platelet count) x N (neutrophil count)/L (lymphocyte count), combines NLR with platelet count and might have a better predictive power than NLR [26]. As a more objective tumor marker, SII reflects the balance between host inflammation and the state of the immune response [27]. 
Table 2 Results of subgroup analysis of pooled hazard ratios of OS of patients with different SII

\begin{tabular}{|c|c|c|c|c|c|}
\hline \multirow[t]{2}{*}{ Stratified analysis } & \multirow[t]{2}{*}{ No. of studies } & \multirow[t]{2}{*}{ Pooled HR $(95 \% \mathrm{Cl})$} & \multirow[t]{2}{*}{ P-value } & \multicolumn{2}{|c|}{ Heterogeneity } \\
\hline & & & & $\mathrm{I}^{2}(\%)$ & $P_{Q}$ \\
\hline \multicolumn{6}{|l|}{ Cancer type } \\
\hline $\mathrm{RCC}$ & 7 & $2.73(1.28,5.81)$ & 0.009 & 99 & $<0.001$ \\
\hline PC & 3 & $2.29(1.44,3.63)$ & $<0.001$ & 46 & 0.160 \\
\hline BC & 2 & $3.01(1.35,6.68)$ & 0.007 & 0 & 0.870 \\
\hline Unclear & 2 & $1.92(1.46,2.54)$ & $<0.001$ & 0 & 0.660 \\
\hline Urothelial cancer & 4 & $2.03(1.55,2.63)$ & $<0.001$ & 0 & 0.730 \\
\hline Non urothelial cancer & 10 & $2.67(1.46,4.88)$ & 0.001 & 98 & $<0.001$ \\
\hline \multicolumn{6}{|l|}{ Study type } \\
\hline Prospective & 1 & $2.99(2.07,4.32)$ & $<0.001$ & NA & NA \\
\hline Retrospective & 13 & $2.55(1.53,4.27)$ & $<0.001$ & 97 & $<0.001$ \\
\hline \multicolumn{6}{|l|}{ Treatment } \\
\hline Surgery & 5 & $1.70(1.04,2.79)$ & 0.030 & 76 & 0.002 \\
\hline Non surgery & 7 & $2.16(1.74,2.68)$ & $<0.001$ & 52 & 0.050 \\
\hline Mix & 2 & $6.67(1.40,31.84)$ & 0.020 & 98 & $<0.001$ \\
\hline \multicolumn{6}{|l|}{ Cut-off value } \\
\hline $0-500$ & 2 & $9.05(2.99,27.41)$ & $<0.001$ & 82 & 0.020 \\
\hline $501-1000$ & 9 & $1.84(1.30,2.59)$ & $<0.001$ & 90 & $<0.001$ \\
\hline$>1000$ & 2 & $3.23(2.38,4.39)$ & $<0.001$ & 0 & 0.450 \\
\hline \multicolumn{6}{|l|}{ Analysis } \\
\hline Multivariate & 10 & $2.06(1.44,2.94)$ & $<0.001$ & 9.1 & $<0.001$ \\
\hline Univariate & 1 & $2.36(1.78,3.13)$ & $<0.001$ & NA & NA \\
\hline
\end{tabular}

$\mathrm{Cl}$ : confidence interval; HR: hazard ratio; OS: overall survival; SII: systemic immune-inflammation index

Table 3 Analyses of secondary outcomes in urologic cancers

\begin{tabular}{|c|c|c|c|c|c|c|}
\hline \multirow{2}{*}{$\begin{array}{l}\text { Secondary } \\
\text { outcomes }\end{array}$} & \multirow[t]{2}{*}{ No. of studies } & \multirow[t]{2}{*}{ No. of cases } & \multirow[t]{2}{*}{ Pooled HR (95\% Cl) } & \multirow[t]{2}{*}{ P-value } & \multicolumn{2}{|c|}{ Heterogeneity } \\
\hline & & & & & $\mathrm{I}^{2}$ & Model \\
\hline PFS & 7 & 1554 & $1.92(1.29,2.88)$ & 0.001 & 93 & Random \\
\hline CSS & 2 & 600 & $2.58(1.36,4.91)$ & 0.004 & 7 & Random \\
\hline ORR & 2 & 448 & $0.40(0.22,0.71)$ & 0.002 & 0 & Fixed \\
\hline DCR & 2 & 448 & $0.93(0.11,8.05)$ & 0.950 & 95 & Random \\
\hline
\end{tabular}

Cl: confidence interval; CSS: cancer-specific survival; DSS: disease-specific survival; ORR: overall response rate; DCR: disease control rate; HR: hazard ratio; SII: systemic immune-inflammation index

SII has been reported in other studies as a predictor for cancer outcomes, such as small cell lung cancer, GI (gastrointestinal) cancer, and hepatocellular carcinoma $[7,8,25]$. The prognostic role of SII in tumors can be explained by the following mechanisms. Numerous studies have reported the relationship between inflammation and cancer and found that cancer-related inflammation is an indispensable component of the tumor microenvironment $[28,29]$. Circulating inflammatory cells, such as neutrophils, lymphocytes, and platelets, play important roles in the development and progression of tumors $[5,33]$. Patients with cancer often suffer from a hypercoagulable state, and platelets can mediate the survival and growth of tumor cells by regulating the formation of micrometastases [30]. Lymphocytes inhibit the proliferation and growth of tumor cells by cytotoxic cell death in cancer immune surveillance and resistance [31, 32]. In addition, neutrophils play an important role in metastasis and progression $[5,33]$. Thus, SII could explain why higher levels of neutrophils and platelets and lower levels of lymphocytes indicate a weak immune response but a strong inflammatory response.

The limitations of this study include the following aspects. First, most of the articles included in this study were retrospective studies, and only one was a prospective study. Second, the number of studies that met the 
Table 4 Results of subgroup analysis of pooled hazard ratios of PFS of patients

\begin{tabular}{|c|c|c|c|c|c|}
\hline \multirow[t]{2}{*}{ Stratified analysis } & \multirow[t]{2}{*}{ No. of studies } & \multirow[t]{2}{*}{ Pooled HR $(95 \% \mathrm{Cl})$} & \multirow[t]{2}{*}{ P-value } & \multicolumn{2}{|c|}{ Heterogeneity } \\
\hline & & & & $\mathrm{I}^{2}(\%)$ & $\mathrm{P}_{\mathrm{Q}}$ \\
\hline \multicolumn{6}{|l|}{ Cancer type } \\
\hline $\mathrm{RCC}$ & 4 & $1.52(0.99,2.31)$ & 0.050 & 91 & $<0.001$ \\
\hline$P C$ & 1 & $11.8(5.6,24.87)$ & $<0.001$ & NA & NA \\
\hline Unclear & 2 & $1.6(1.23,2.07)$ & $<0.001$ & 0 & 0.900 \\
\hline Urothelial cancer & 2 & $1.6(1.23,2.07)$ & $<0.001$ & 0 & 0.900 \\
\hline Non urothelial cancer & 5 & $2.31(1.23,3.69)$ & 0.007 & 95 & $<0.001$ \\
\hline \multicolumn{6}{|l|}{ Treatment } \\
\hline Surgery & 2 & $1.16(0.8,1.7)$ & 0.430 & 62 & 0.110 \\
\hline Non surgery & 4 & $2.65(1.53,4.58)$ & $<0.001$ & 88 & $<0.001$ \\
\hline Mix & 1 & $1.43(0.89,2.3)$ & 0.140 & NA & NA \\
\hline \multicolumn{6}{|l|}{ Study type } \\
\hline Prospective & 1 & $1.43(0.89,2.3)$ & 0.140 & NA & NA \\
\hline Retrospective & 6 & $2.03(1.29,3.2)$ & 0.002 & 94 & $<0.001$ \\
\hline \multicolumn{6}{|l|}{ Analysis } \\
\hline Multivariate & 5 & $1.93(1.14,3.29)$ & 0.010 & 93 & $<0.001$ \\
\hline Univariate & 2 & $1.91(1.53,2.38)$ & $<0.001$ & 0 & 0.550 \\
\hline
\end{tabular}

$\mathrm{Cl}$ : confidence interval; HR: hazard ratio; OS: overall survival; SIl: systemic immune-inflammation index

requirements was not that large, and the sample size included was relatively small, especially in the subgroup analysis. Third, the cut-off values of SII varied in different studies, and the calculation methods were inconsistent. A few studies did not provide multivariate analysis results, so we used univariate results instead. Finally, despite the subgroup analysis and the sensitivity analysis being performed, we were not able to confirm whether different types of tumors and different treatments would lead to bias in the results.

In conclusion, the outcomes presented in this metaanalysis indicated that high SII was independently related to poor prognosis in patients with urologic cancers. SII could be a significant and cost-effective prognostic indicator for urinary cancers. Of course, well-designed, large-scale multicenter studies are needed to validate the clinical value of SII as a prognostic biomarker for urologic cancers.

\section{Authors' contributions}

YLH, HPL: protocol/project development; YLH, HPL, YSW: data collection or management; HPL, YFG: data analysis; YLH, HPL, YSW: manuscript writing/editing. All authors read and approved the final manuscript.

\section{Funding}

No specific funding has been received for the present study.

\section{Availability of data and materials}

The datasets used in this study are available from the corresponding author upon reasonable request.

Ethics approval and consent to participate Not applicable.
Consent for publication

Not applicable.

\section{Conflict of interests}

We declare that we have no conflict of interest.

\section{Author details}

1 Department of Radiology, The First People's Hospital of Chongqing Liang Jiang New Area, Chongqing, China. ${ }^{2}$ Department of Urology Surgery, The First Affiliated Hospital of Chongqing Medical University, Chongqing, China.

${ }^{3}$ Department of Urology Surgery, The Second People's Hospital of Chengdu, Chengdu, Sichuan, China. ${ }^{4}$ Chongging Key Laboratory of Molecular Oncology and Epigenetics, The First Affiliated Hospital of Chongqing Medical University, 1 Youyi Road, Yuzhong District, Chongqing 400042, People's Republic of China.

${ }^{5}$ Department of Intensive Care Unit, Affiliated Hangzhou First People's

Hospital, Zhejiang University School of Medicine, 261 Huansha Road, Hang-

zhou 310006, Zhejiang, People's Republic of China.

Received: 13 July 2020 Accepted: 1 October 2020

Published online: 12 October 2020

References

1. Rini BI, Campbell SC, Escudier B. Renal cell carcinoma. Lancet. 2009;373(9669):1119-32.

2. Siegel RL, Miller KD, Jemal A. Cancer statistics, 2016. CA Cancer J Clin. 2016;66(1):7-30.

3. Gilbert SM, Wood DP, Dunn RL, et al. Measuring health-related quality of life outcomes in bladder cancer patients using the Bladder Cancer Index (BCI). Cancer-Am Cancer Soc. 2007;109(9):1756-62.

4. Katzenwadel A, Wolf P. Androgen deprivation of prostate cancer: leading to a therapeutic dead end. Cancer Lett. 2015;367(1):12-7.

5. Bausch D, Pausch T, Krauss T, et al. Neutrophil granulocyte derived MMP-9 is a VEGF independent functional component of the angiogenic switch in pancreatic ductal adenocarcinoma. Angiogenesis. 2011;14(3):235-43.

6. Minami S, Ihara S, Kim SH, Yamamoto S, Komuta K. Lymphocyte to Monocyte Ratio and Modified Glasgow Prognostic Score Predict Prognosis of Lung Adenocarcinoma Without Driver Mutation. World J Oncol. 2018;9(1):13-20. 
7. Miao Y, Yan Q, Li S, Li B, Feng Y. Neutrophil to lymphocyte ratio and platelet to lymphocyte ratio are predictive of chemotherapeutic response and prognosis in epithelial ovarian cancer patients treated with platinumbased chemotherapy. Cancer Biomark. 2016;17(1):33-40.

8. Zhou X, Xu L, Huang Z, et al. The hematologic markers as prognostic factors in patients with resectable gastric cancer. Cancer Biomark. 2016;17(3):359-67.

9. Lolli C, Caffo O, Scarpi E, et al. Systemic immune-inflammation index predicts the clinical outcome in oatients with MCRPC treated with abiraterone. Front Pharmacol. 2016;7:376.

10. Zhong JH, Huang DH, Chen ZY. Prognostic role of systemic immuneinflammation index in solid tumors: a systematic review and meta-analysis. Oncotarget. 2017:8(43):75381-8.

11. Chen C, Peng GE, Bai Y, Zhao Z, Ren L. CRP/Alb ratio in the prognosis of lung cancer. Lab Med. 2017.

12. De Giorgi U, Procopio G, Giannarelli D, et al. Association of systemic inflammation index and body mass index with survival in patients with renal cell cancer treated with nivolumab. Clin Cancer Res. 2019;25(13):3839-46.

13. Fan $L$, Wang $R$, Chi C, et al. Systemic immune-inflammation index predicts the combined clinical outcome after sequential therapy with abiraterone and docetaxel for metastatic castration-resistant prostate cancer patients. Prostate. 2018;78(4):250-6.

14. Lolli $C$, Basso U, Derosa $L$, et al. Systemic immune-inflammation index predicts the clinical outcome in patients with metastatic renal cell cancer treated with sunitinib. Oncotarget. 2016;7(34):54564-71.

15. Zhang W, Wang R, Ma W, et al. Systemic immune-inflammation index predicts prognosis of bladder cancer patients after radical cystectomy. Ann Transl Med. 2019;7(18):431.

16. Chrom P, Zolnierek J, Bodnar L, Stec R, Szczylik C. External validation of the systemic immune-inflammation index as a prognostic factor in metastatic renal cell carcinoma and its implementation within the international metastatic renal cell carcinoma database consortium model. Int J Clin Oncol. 2019;24(5):526-32.

17. Gorgel SN, Akin Y, Koc EM, Kose O, Ozcan S, Yilmaz Y. Retrospective study of systemic immune-inflammation index in muscle invasive bladder cancer: initial results of single centre. Int Urol Nephrol. 2020;52(3):469-73.

18. Jan $\mathrm{HC}$, Yang $\mathrm{WH}, \mathrm{Ou} \mathrm{CH}$. Combination of the preoperative systemic immune-inflammation index and monocyte-lymphocyte ratio as a novel prognostic factor in patients with upper-tract urothelial carcinoma. Ann Surg Oncol. 2019;26(2):669-84.

19. Man YN, Chen YF. Systemic immune-inflammation index, serum albumin, and fibrinogen impact prognosis in castration-resistant prostate cancer patients treated with first-line docetaxel. Int Urol Nephrol. 2019;51(12):2189-99.

20. Ozbek E, Besiroglu H, Ozer K, Horsanali MO, Gorgel SN. Systemic immune inflammation index is a promising non-invasive marker for the prognosis of the patients with localized renal cell carcinoma. Int Urol Nephrol. 2020;52(8):1455-63.
21. Barua SK, Singh Y, Baruah SJ, et al. Predictors of progression-free survival and overall survival in metastatic non-clear cell renal cell carcinoma: a single-center experience. World J Oncol. 2019;10(2):101-11.

22. Rebuzzi SE, Buti S, Sbrana A, et al. Baseline lymphocyte to monocyte ratio (LMR) and systemic inflammation index (SII) as prognostic factors in metastatic renal cell carcinoma ( $\mathrm{mRCC}$ ) patients treated with nivolumab: Preliminary results of the Meet-URO 15 (I-BIO-REC) study. J Clin Oncol. 2020;38(6)

23. Ghanghoria A, Barua SK, Rajeev TP, et al. Influence of inflammatory markers on the prognosis of rare kidney cancers with variant histology. Indian J Urol. 2020;36(5):S17-8.

24. Palacka P, Mego M, Mikulova T, et al. Systemic immune-inflammation index to predict survival in Caucasian patients with metastatic urothelial carcinoma. J Clin Oncol. 2017;35(15).

25. Hong X, Cui B, Wang M, Yang Z, Wang L, Xu Q. Systemic immune-inflammation index, based on platelet counts and neutrophil-lymphocyte ratio, is useful for predicting prognosis in small cell lung cancer. Tohoku J Exp Med. 2015;236(4):297-304.

26. Aziz MH, Sideras K, Aziz NA, et al. The systemic-immune-inflammation index independently predicts survival and recurrence in resectable pancreatic cancer and its prognostic value depends on bilirubin levels: a retrospective multicenter cohort study. Ann Surg. 2019;270(1):139-46.

27. Zhang Y, Lin S, Yang X, Wang R, Luo L. Prognostic value of pretreatment systemic immune-inflammation index in patients with gastrointestinal cancers. J Cell Physiol. 2019;234(5):5555-63.

28. Mezouar S, Frere C, Darbousset R, et al. Role of platelets in cancer and cancer-associated thrombosis: experimental and clinical evidences. Thromb Res. 2016;139:65-76.

29. Swierczak A, Mouchemore KA, Hamilton JA, Anderson RL. Neutrophils: important contributors to tumor progression and metastasis. Cancer Metastasis Rev. 2015:34(4):735-51.

30. Huang L, Liu S, Lei Y, Wang K, Yuan X. Systemic immune-inflammation index, thymidine phosphorylase and survival of localized gastric cancer patients after curative resection. Oncotarget. 2016;7(28):44185-93.

31. Mantovani A, Allavena P, Sica A, Balkwill F. Cancer-related inflammation. Nature. 2008;454(7203):436-44.

32. Labelle M, Begum S, Hynes RO. Direct signaling between platelets and cancer cells induces an epithelial-mesenchymal-like transition and promotes metastasis. Cancer Cell. 2011;20(5):576-90.

33. Tan KW, Shu ZC, Wong FHS, et al. Neutrophils contribute to inflammatory lymphangiogenesis by increasing VEGF-A bioavailability and secreting VEGF-D. Blood. 2013;122(22):3666-77.

\section{Publisher's Note}

Springer Nature remains neutral with regard to jurisdictional claims in published maps and institutional affiliations.

Ready to submit your research? Choose BMC and benefit from

- fast, convenient online submission

- thorough peer review by experienced researchers in your field

- rapid publication on acceptance

- support for research data, including large and complex data types

- gold Open Access which fosters wider collaboration and increased citations

- maximum visibility for your research: over 100M website views per year

At $\mathrm{BMC}$, research is always in progress.

Learn more biomedcentral.com/submissions 